\title{
Waiting times and patient satisfaction in the accident and emergency department
}

\author{
A. J. BOOTH*, C. J. HARRISON*, G. J. GARDENER ${ }^{+} \&$ \\ A. J. GRAY ${ }^{\dagger}$ \\ * Manchester University Medical School, Stopford Building, Oxford Road, Manchester \\ and Department of Accident and Emergency Medicine, Stockport Infirmary, Wellington \\ Road South, Stockport, Cheshire.
}

\section{SUMMARY}

A survey of the waiting times and patients' opinions of these times was undertaken in a busy district general hospital A\&E department. The various components of the overall waiting time are analysed and specific points of the patients' attendance, where waiting times were prolonged, are identified. Standards are derived which is hoped may result in $75 \%$ of patients being satisfied with the duration of their wait. The current levels of achievement are compared with these standards. Suggested and actual improvements to the department to improve our performance are described.

\section{INTRODUCTION}

The National Health Service is increasingly regarding patients as consumers of a service, and, as such, aims to provide 'consumer satisfaction'. This is particularly important in the A\&E department, which has been viewed as the 'shop window' of the hospital service. More people are seen in A\&E than in any other hospital department and the public perception of the hospital service may be based purely on this department. The length of time spent waiting in the department generates a large number of complaints by patients and is an area which needs to be improved. However, there have been few reports on waiting times in U.K. A\&E departments (Lewis, 1981; Mitchell, 1987). These studies have concentrated on actual waiting times and have not considered the patients' perception of their wait.

Correspondence: $\mathrm{Mr}$ Alistair J. Gray, Consultant in Accident and Entergency Medicine, Stockport Infirmary, Wellingtion Road South, Stockport, Cheshire, SK1 3UJ. 
This study investigated the length of time patients were prepared to wait before they became dissatisfied. Our study was confined to 'walking wounded' patients, who form the bulk of the workload.

\section{The department}

The A\&E department chosen for this study has a catchment area of over 300000 people in the Stockport area and, in addition, patients from West Derbyshire. In 1988, this department saw 54168 new and 17554 review patients.

\section{Staffing}

The department is staffed by a consultant, a senior registrar, an associate specialist, six senior house officers (SHOs) and six clinical assistant sessions. Two SHOs are present from $8.00 \mathrm{a} . \mathrm{m}$. to midnight and one from midnight to $8.00 \mathrm{a} . \mathrm{m}$.

During the morning and afternoon, 10 nurses (including students) are on duty, while in the evening there are seven. At night, five or six trained nurses are present. Nurses operate a triage system during the daytime and intermittently during the evening where patients are prioritized according to the severity of their injury or illness. After 1130 p.m. no receptionist is on duty and nurses book patients in and simultaneously operate an informal triage system. The A\&E X-ray Department is staffed by at least two radiographers from 9.00 a.m. to 11.30 p.m. An on-call service exists overnight.

\section{PATIENTS AND METHODS}

Two parallel studies were conducted over 7 consecutive days during school termtime. All 'walking wounded' patients who attended the department during this period who were not subsequently admitted were eligible for inclusion in the studies. Walking wounded patients were defined as those not brought in by ambulance.

In the first study on objective waiting times, a slip, detailing the components of the total waiting time, was attached to the front of the casualty card and completed by the staff (Appendix 1).

For the second study, a questionnaire was completed by the patients which detailed their opinions of the acceptability of the various components of their total wait (Appendix 2).

\section{RESULTS}

Results were analysed using the Statistical Package for the Social Sciences on an IBM-PC computer. For each waiting time, the mean, standard deviation and median were calculated. Waiting times were assessed according to time and day of arrival. Staff timing slips and patient questionnaires were compared by using 
Spearman's ranked correlation coefficient. For each wait, target times and minimum standards were determined. The target time was defined as the time in which at least $75 \%$ of patients regarded the waiting time as excellent or good. The minimum standard was defined as the time in which at least $75 \%$ of patients regarded the waiting time as excellent, good or reasonable. The actual times were derived $\stackrel{5}{\circ}$ from the cumulative frequency distribution for patient replies which fell into one or other of the above categories. The time at the 75th centile was taken as the standard. As the times were taken from separate distributions there is no direct relationship between the two standards.

A total of 758 staff timing slips were returned. Of the patients studied, $624 \stackrel{\mathrm{C}}{\mathrm{C}}$ (82.3\%) were seen by a triage nurse, $380(50.1 \%)$ were X-rayed and $574(75.7 \%)$ required some form of treatment. The results of the objective timing study are $\vec{\omega}$ shown in Table 1. Table 2 demonstrates the diurnal variation in the arrival of $\frac{\Phi}{\Phi}$ patients over the study period and the effect this has on waiting times. Table 33 demonstrates the day-to-day variation.

Questionnaires were received from 342 patients, representing a response rate $\vec{\circ}$ of $45.1 \%$. The results are shown in Table 4 . This response rate is somewhat disappointing. However the two groups (i.e. those who replied and those who did not) have been compared using a Mann Whitney $U$-test. This was performed for each component time of the patients' wait and also for the time of attendance. The day of attendance was also studied using a Pearson Chi-squared test. In only one $\vec{\bullet}$ case was there a significant difference. This was in the overall waiting time where $\stackrel{\circ}{?}$ patients who waited longer were less likely to fill in their forms (2-tailed $P=0.042$

Table 1. Objective waiting times in minutes and correlation with subjective opinions.

\begin{tabular}{lrccc}
\hline Wait for & Mean (SD) & Median & $\begin{array}{c}\text { Spearman } \\
\text { corr. }\end{array}$ & $P$ \\
\hline Triage nurse & $16(18.4)$ & 10 & 0.51 & $<0.001$ \\
Doctor after triage & $47(40.6)$ & 35 & 0.65 & $<0.001$ \\
Reception-triage-doctor & $60(44.9)$ & 47 & - & - \\
Doctor if not triaged & $46(46.6)$ & 30 & 0.43 & $<0.05$ \\
X-ray after seeing doctor & $27(20.3)$ & 20 & 0.47 & $<0.001$ \\
Doctor after X-ray & $25(19.0)$ & 20 & & \\
Treatment if not X-rayed & $25(30.2)$ & 15 & 0.15 & NS \\
Treatment if X-rayed & $21(28.9)$ & 10 & 0.22 & $<0.05$ \\
Overall waiting time & $111(60.4)$ & 105 & 0.48 & $<0.001$ \\
\hline
\end{tabular}

Table 2. Effect of time of arrival on waiting time for doctor.

\begin{tabular}{lrlc}
\hline Time & \multicolumn{2}{c}{ No. arriving (\%) } & Mean waiting time (min) \\
\hline $0900-1259$ & 210 & $(27.7)$ & 56 \\
$1300-1659$ & 200 & $(26.4)$ & 61 \\
$1700-2059$ & 217 & $(28.6)$ & 62 \\
$2100-2359$ & 60 & $(7.9)$ & 53 \\
$2400-0900$ & 71 & $(9.4)$ & 42 \\
\hline
\end{tabular}


Table 3. Effect of day of arrival on waiting time for doctor

\begin{tabular}{lrlc}
\hline Day & No. arriving (\%) & Mean waiting time (min) \\
\hline Monday & 132 & $(17.4)$ & 54 \\
Tuesday & 122 & $(16.1)$ & 41 \\
Wednesday & 109 & $(14.4)$ & 36 \\
Thursday & 88 & $(11.6)$ & 35 \\
Friday & 95 & $(12.5)$ & 60 \\
Saturday & 90 & $(11.9)$ & 71 \\
Sunday & 122 & $(16.1)$ & 105 \\
\hline
\end{tabular}

Table 4. Patients' views on waiting times.

\begin{tabular}{lcccc}
\hline Waiting time for & Excellent & Good & Reasonable & Too long \\
\hline Triage nurse & 34.3 & 29.0 & 25.2 & 11.5 \\
Doctor after triage & 15.4 & 19.1 & 29.0 & 36.4 \\
Doctor if not triaged & 8.2 & 38.8 & 38.8 & 14.3 \\
Before and after X-ray & 15.6 & 26.6 & 26.6 & 31.3 \\
Treatment & 29.6 & 22.6 & 25.2 & 22.6 \\
Overall waiting & 17.8 & 20.5 & 27.1 & 34.7 \\
\hline
\end{tabular}

(all figures are percentages)

Because of inadequate completion, only 240 questionnaires could be matched with the staff timing slips. The Spearman's rank correlation coefficients (and significance levels) are shown in Table 1. The target times and minimum standards are shown in Table 5. Current levels of achievement are also shown in this table as percentages of patients treated within the defined times.

Of patients, $38.6 \%$ made some comment in the 'suggested improvements' section of the form. A total of $48.5 \%$ felt that extra staff were needed, $9.8 \%$ wanted political change to effect improvements, $11.4 \%$ felt general facilities should be improved and $30.3 \%$ gave mixed responses which could not be categorized.

\section{DISCUSSION}

It was the feeling of both medical and nursing staff in the department that the waiting times were not excessive. However, when audited, this belief was found to be false, especially during certain periods or during certain stages of an individual visit.

Our results agree with similar studies that have shown Monday to be the busiest day (Williams, 1984). This is not surprising as many people injure themselves during the weekend but do not consider they need immediate treatment. However, the longest waits occurred at the weekend (Table 3) when fewer medical and nursing staff are on duty. Contrary to previous studies (Dixon, 1971; Naylor 
Table 5. Target times, minimum standard times and present levels of achievement.

\begin{tabular}{lcc}
\hline Waiting for & $\begin{array}{c}\text { Target time (mins) } \\
\text { (\% patients currently } \\
\text { seen within target time) }\end{array}$ & $\begin{array}{c}\text { Minimum standard (mins) } \\
\text { (\% patients currently seen } \\
\text { within minimum standard) }\end{array}$ \\
\hline Triage nurse & $15(72)$ & $100(100)$ \\
Doctor after triage & $10(17)$ & $60(74)$ \\
Doctor is not triaged & $17(20)$ & $60(81)$ \\
Before and after X-ray & $20(12)$ & $45(53)$ \\
Overall waiting time & $30(7)$ & $90(41)$ \\
\hline
\end{tabular}

1982), we found the early evening to be equally as busy as the morning. This could be because many general practitioners (GPs) have an early evening surgery which may lead to a referral to the A\&E department or patients may choose to visit the department on returning from work.

Our figures for average waiting times compare poorly with a previous study in Northampton (Mitchell, 1987) which found the mean waiting time to see the doctor to be $24 \mathrm{~min}$ (compared with our $57 \mathrm{~min}$ ), and the overall waiting time to be $70 \mathrm{~min}$ (compared with $111 \mathrm{~min}$ in our study). However the present study was designed to identify more closely the specific areas where delay occurred (Appendix 1).

Evidence of the need for improvement is provided by our performance when judged against the target times and minimum standard times. This is particularly true for the overall waiting time spent in the department and in the wait before and after X-ray (Table 5). However, attainment of some of the target times seems difficult with present levels of staff and facilities.

On the other hand, it must be said that the majority of patients regarded our performance as satisfactory (Table 4). Particularly good results were achieved in the wait for the triage nurse. It is clear that the patients who pass through the department appreciate the attention of a triage nurse. However, according to our results, the triage system does increase the overall time a patient has to wait to see the doctor and this seems to be reflected by the poor satisfaction with the wait following attention from the triage nurse (Tables $1 \& 4$ ). Although the triage nurse institutes no active treatment, other than to make the patient comfortable, and to grade the patient according to need, the attention may lead a patient to believe that he/she is 'in the system' and will not wait too much longer. Additionally this result could be explained by the fact that patients often do not see a triage nurse at quiet times and instead are taken straight through to see a doctor.

Although the need for improvement is clear, the methods by which this could be brought about are less evident. As the patients suggested, more staff would be likely to improve matters. The current British Association for Accident and Emergency Medicine guidelines for medical staffing of A\&E departments are as follows:

- One senior house officer per 5000 new patients

- One consultant per 20000 new patients

- Two consultants if number of new patients exceeds 50000 per annum 
- Plus a full complement of middle grade staff

However, to enlarge just one category of staff could simply lead to a bottleneck elsewhere in the system (as in X-ray in this study). The extra staff are particularly needed at the weeked when the longest waits occur. It would seem to make sense to increase the number of staff on duty at weekends to the normal full weekday complement of staff wherever possible.

As a result of this audit, there have been several improvements to the Stockport A\&E Department:

(1) One of the clinical assistant sessions has been re-designated to Sunday afternoon;

(2) Facilities now exist for a second dedicated A\&E X-ray room to improve the waiting time which was considered 'too long' (Table 4);

(3) There is know an extra radiographer on-call between 9.00 a.m. and 12.00 p.m. to assist in A\&E if waiting times for $\mathrm{X}$-ray are excessive;

(4) A specific nurse is designated to collect the X-rays, marry them with the A\&E record, and inform the doctor that the films are available and;

(5) There have been three extra SHO sessions allocated to the A\&E department.

Numbers of patients returning to review clinics and nurse dressing clinics, should be kept as low as possible, so that staff and facilities are available to deal with new attenders. Mitchell (1987) suggested starting these clinics earlier in the morning when the department is usually somewhat quieter.

If the waiting time cannot be reduced then at least the wait could be made more tolerable by improving the facilities for patients. At present at Stockport Infirmary, the waiting room includes a small play area for children and a television showing a 3-h videotape. As well as containing general entertainment programmes, a number of medical and health education topics are also included. (This is popular with the patients.) Drinks machines are available in the corridor outside the department and a public telephone is also available. Some of the comments on the patients' questionnaire made a plea for more comfortable chairs and easier access to food and drinks. Other suggestions from the patients included the provision of more staff (64 replies) and political change (13 replies) Finally, Shelley \& Shelley (1987) suggested, no doubt tongue in cheek, issuing a lottery ticket for every $15 \mathrm{~min}$ that patients were kept waiting beyond a specified limit.

The problem of outpatient waiting times is currently being addressed within recent government initiatives. Scant mention is made of $A \& E$ waiting times despite the fact that almost as many patients attend the A\&E service per year as attend the outpatient department. This appears to be yet another example of the low priority afforded the specialty of A\&E medicine.

\section{CONCLUSION}

The waiting times for an average week in a busy district general hospital A\&E department has been assessed, together with patients' perception of what is acceptable. We have been able to calculate a series of minimum and ideal target waiting times. 
As a direct result of this study there have been five specific alterations to the staffing or management of the Department in order to to improve patient throughput. As ever, the Department will continue to strive to improve the service. However, limitations of staff and facilities will be the main impediments.

\title{
REFERENCES
}

Dixon P. (1971) Casual attendance at an accident department and a health centre. British Medical Journal ڤ 41, 214.

Lewis B. (1981) Accident and Emergency Services. Part of a research project by the Community Health Council in the North Western Region, 1981.

Mitchell F. P. (1987) Timeliness of care in the accident and emergency department. Hospital and Health Services Review, 127-131.

Naylor A. (1982) The Bradford Accident Service. Injury 3, 148.

Shelley W. B. \& Shelley E. D. (1987) A new office waiting game. New England Journal of Medicine 317, iv 967.

Williams K. (1984) Who uses the Accident Service? Injury 16, 35-37.

\author{
APPENDIX 1 \\ Objective waiting times \\ Time when seen by receptionist \\ Time when seen by triage nurse \\ Time when seen by doctor \\ Time of X-ray (taken from clock on films) \\ Time when seen by doctor after X-ray \\ Time when treatment started \\ Time of discharge
}

\section{APPENDIX 2}

Patients' opinions of waiting times

Comment

Waiting time for:

(Excellent/Good/Reasonable/Too long)

Triage nurse

Doctor

Doctor after X-Ray

Treatment

Overall waiting time

'How do you think we could improve the service?' 